\title{
Retrospective Application of New Pediatric Ventilator-Associated Event Criteria in a Tertiary Pediatric Intensive Care Unit
}

\author{
Aybüke Akaslan Kara ${ }^{1}$, Ekin Soydan², Elif Kıymet ${ }^{2}$, Elif Böncüoğlu ${ }^{2}$, Nevbahar Demiray ${ }^{2}$, \\ Yeliz Oruç $^{2}$, İlknur Çağlar ${ }^{2}$, Nuri Bayram², Hasan Agın², and ilker Devrim² \\ ${ }^{1}$ Dr. Behçet Uz Çocuk Hastalıkları Eğitim ve Araştırma Hastanesi \\ ${ }^{2}$ Dr Behcet Uz Child Disease and Surgery Training and Research Hospital
}

November 12, 2020

\begin{abstract}
Background:. In January 2020 a modification is applied for pediatric ventilator associated events (Ped-VAE) surveillance by Center for Disease Control and Prevention. İn this study we investigate the potential impact of this newly criteria and determine whether the adult ventilator-associated conditions (VAC), infection-related ventilator-associated complications (IVAC) and possible ventilator-associated pneumonia (PVAP) criteria could be applied pediatric patients with ped-VAE Methods:. We analyzed data between January 2014 and December 2019 using the new ped-VAE criteria. We compared two different criteria for identifying VAE: the 2013 adult VAE criteria, and the newly ped-VAE criteria. Result: The data of 91 VAE patients were evaluated, $42.8 \%$ were not categorized as ped-VAE and $57.2 \%$ patients were compatible with the ped-VAE , $19.2 \%$ were categorized as adult VAC, $21.1 \%$ were categorized as IVAC, and $59.6 \%$ patients were categorized as PVAP. There was no significant difference between mortality and the diagnostic ventilator surveillance types. Conclusions: Pediatric ventilatorassociated event algorithm is a better tool for children than the VAE algorithm defined for adults and the new pediatric criteria are more effective in detecting ventilator assosiated complications in children. We think further studies will be needed for evaluate ped VAE criteria.
\end{abstract}

\section{Hosted file}

VAE pediatric pulmonology yeni.pdf available at https://authorea.com/users/375293/articles/ 492583-retrospective-application-of-new-pediatric-ventilator-associated-event-criteriain-a-tertiary-pediatric-i\%CC\%87ntensive-care-unit

\section{Hosted file}

tables vae pediatric pulmonology.pdf available at https://authorea.com/users/375293/articles/ 492583-retrospective-application-of-new-pediatric-ventilator-associated-event-criteriain-a-tertiary-pediatric-i\%CC\%87ntensive-care-unit 